Journal of

Applied Crystallography

ISSN 0021-8898

\section{Fourth European Crystallography Prize}

The European Crystallographic Association (ECA) invites nominations for the fourth European Crystallography Prize to recognize a significant achievement or discovery in crystallography in the past 5-10 years. Nominees should be affiliated or identified with the European crystallographic community, as broadly defined in the charter of the ECA (see the ECA-news site, www.ecanews.org)

The prize, including a monetary award and certificate of recognition, will be awarded at the opening ceremony of the 22nd European Crystallography Meeting (ECM-22) to be held in Budapest, Hungary, 26-31 August 2004. The previous laureates are: 2000, Professor Ada Yonath, Weizmann Institute of Science, Israel; 2001, Professor Jochen R. Schneider, HASYLAB at DESY, Germany; 2003, Professor Carmelo Giacovazzo, University of Bari, Italy.

\title{
crystallographers
}

Nominations for the prize should include a statement of the contribution for which the prize is to be awarded and a short curriculum vitae of the nominee. The nominations should be sent by e-mail or by regular mail no later than 28 February 2004 to: Professor Anders Liljas, Molecular Biophysics, Center for Chemistry and Chemical Engineering, Lund University, Box 124, SE22100 Lund, Sweden (telephone: +46-4622246 81; fax: +46-46-222 46 92; e-mail: anders.liljas@mbfys.lu.se).

\section{Margaret C. Etter Early Career Award presented to Julia Chan}

This award recognizes achievement and future potential among those at an early stage in their independent careers. The award was established to honor the memory and celebrate the scientific accomplishments and mentoring skills of the late Professor Margaret C. Etter, and was given for the first time to Dr Julia Y. Chan (Assistant
Professor, Department of Chemistry, Louisiana State University, Baton Rouge, LA, USA), in recognition of her outstanding achievements in the study of materials chemistry using crystallographic methods, her excellent leadership in teaching and mentoring, and her exceptional potential to continue to impact crystallographic research and education. Julia presented her award lecture: 'Structure-Property Relationships of Superconducting and Heavy Fermion Intermetallics' at the Etter Award Symposium which was organized by Jeanette Krause Bauer and chaired by Carolyn Brock.

In addition several students were chosen by Special Interest Groups to receive the first Etter Student Lecturer Awards. They were: David Lodowski (Biological Macromolecules), Monica Allain (Small-Angle Scattering), Peter Chupas (Materials Science), Jennifer Padilla (General Interest) and Firas Awwadi (Small Molecules). 